SLAC/AP- -54

DE87 003667

SLAC / A P-54

November 1986

(AP)

\title{
A NOTE ON THE RELATIONSHIP BETWEEN \\ THE EMITTANCE, THE BETA FUNCTION AND THE ENERGY IN A LINEAR COLLIDER
}

\author{
JOHN REES \\ - Staryond Linear Aetelemitor Centar \\ Stanford University, Stanjond, California, 0/305
}

Congider the ecaling lawa for linesr colliders for the case of laterally round Gaustian bearns and for the case that mutul pinching of the beams can be ignored. III We choose thewe simple tases to make a point. Later we shatl alter the law to take account of the pinch.

$$
\begin{gathered}
L=\frac{f N^{3}}{A}, \\
P_{t}=f N E, \\
D=\frac{4 \pi r_{e} m_{t} \mathrm{c}^{5} \sigma_{z} N}{A E}, \\
\delta=2 . \pi 1 \frac{\mathrm{r}_{\mathrm{d}}^{3} N^{2} E}{m_{\varepsilon} e^{3} A \sigma_{*}},
\end{gathered}
$$

where $L$ is the luminosity, $P$ is the power in euch beam, $E$ la the energy of each beam, $D$ is the disruption parameter and 6 is the mean fractional cnergy spread of particles that have passed through the opposing bunch due to their emiasion

'Work supported by the Department of Enersy, contract DE-AC03-765F00515. 


\section{MASTER}

of classical radiution in the collective field of that bunch. (We shall demonstrate later that the clavical approximation is valid in the cases with which we shall be dealing.) Further, $\boldsymbol{N}$ is the frequency of bunch collisions, $N$ is the number of particles in a bunch, $A$ is the effective inleraction area, $r$ is the clarical redius of the electron and $\sigma_{p}$ b the bunch length (stendurd deviation). The meanings of the other aymbols are obvious.

These equations may be solved for $A, N, f$ and $\sigma_{x}$ (the accelentor purameterd) in term of $E, L, D, \delta$ and $P$ (the performence and featibitity parametern), giving \& unique spectifation for the former set of variables once the Intter set is chosen. In this note we shall concentrate on one of the equationa so obtained,

$$
A(D, L, D, \delta, P)
$$

and require the luminoefity to vary $a B^{2}$. We thall ind as a result that the collider's enersy is rather otrongly reatrieted by the beam-forming technolosy we can hope to achieve.

The effective interaction area is

$$
A=\mathbf{4} \pi \sigma_{?}^{2}
$$

where $\sigma_{r}$ is the radial atendard deviation of the tranoverse distribution of thr interacting beamu. In terms of the bets function at the interaction region, $\boldsymbol{\beta}^{*}$, and the normaljed emittance, $c_{n}$, of the beam from the accelerators asouming no pinch it is

$$
A=4 \pi m_{\varepsilon} c^{2} \epsilon_{m} \beta^{*} / E
$$

where $E$ is the beam energy.

DISCLAIMER

This report wes prepared as an axcount of work sponsored by an agency of the United States Government. Neither the United States Government nor any agency thereof, nor any of their cmployees, makes any warranty, express or impliod, or assumes any legal liability or responsibility for the aceuracy, completentess, or usefulness of any information, apparatus, product, or process disclosed, or represents that its use would not infringe privately owed rights Reference herein to any specific commercil product, process, or service by trade name, trademark, mannfacturer, or otherwise doex not necossarily constitute of imply its endorsement, recommendation, er fovoring by the United Stales Government of any agency thereof. The viewa and opinions of autbors expresed berein do not pecessarily steve or rellect those of the Ujited States Goverement at any agency thereot. 
Equations (1) through (A) can be solved for $A, f, N$ and $\sigma_{k}$, and in particular the reault for $A b^{|2|}$

$$
A=\frac{1}{2.71(4 \pi)}\left(\frac{P^{3} D S}{r^{2} D^{3}}\right)
$$

The luminosity must scale as $E^{2}$, wo the interaction arat varies a $E^{-9}$, a powerful dependence! Taking this fact logether with $\mathrm{Eq}$. (6) and $\mathrm{Eq}$. (7), we may write the equation

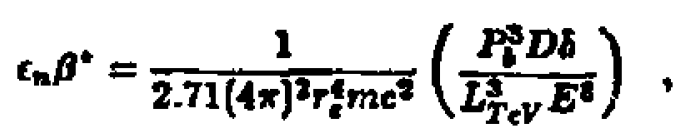

where $L_{\mathrm{T}, V}$ is the luminosity for a beam energy of $1 \mathrm{TeV}\left(\vec{b}_{\mathrm{cm}}\right.$ of $2 \mathrm{TeV}$ ). The value required for the product $\left(\epsilon_{n} \beta^{-}\right)$varies as $E^{-a}$ once we have fixed the factors in the numerator at values as large $m$ the low or the trafie permits.

Conversely, the enera $y$ we can reach with the apecified values of $L_{T e V}, E, P_{\text {, }}$ $D$ and $\delta$ varie only as the cighth root of the amalest vilue of $\left(f_{4} \beta^{\prime}\right)$ we car achieve in practice. This is a very weak dependence. It implies ihat even if we are able to reduce the attainsble value of $\left(\epsilon_{n} \beta^{*}\right)$ to one thousandth of the value we can now reach, we shall incrense the collider ener;y by only a factor of 2.4. Whether such a weak dependence create a serioun threst to future colliders depends on the numbers we can revonably attach to the variables, but before we investigate that question, we should correct $\mathrm{Eq}$. (8) to take account of the pinch.

Consider the simplified picture of beams pinching ench other shown in Fig. 1 The symbol $A$ is meant to stand for the actual effective interaction area - that which would result from measuring the luminosity and solving $\mathrm{Eq}$ - (1) for $A$. $A_{a}$ is the ellective interaction area which would previl if the pinch were turned ofl" "II We might eall it the incoming aree. It is the area determined by the emittance and beta lunction produced by the accelerators of the coltider. In other Fords, $\mathrm{Eq}$. (6) should be replaced by

$$
A_{0}=4 \pi m_{e} e^{2} c_{s} \beta^{*} / B
$$


Aleo the disruption parameter fo cuatomarily defined in terms of this area.

$$
D_{0}=\frac{4 \pi r_{e} m_{e} c^{2} \sigma_{n} N}{A_{0} E}
$$

This equation replaces Eq. (3).

The enhancement factor, $\boldsymbol{H}$, in $^{101}$

$$
H\left(D_{\mathrm{s}}\right)=\frac{A_{0}}{A},
$$

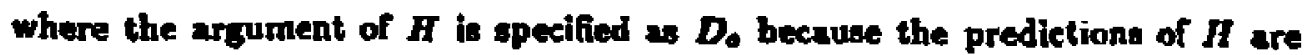
presented in term of it. We ean now replece Eq. (B) with the improved form

$$
\epsilon_{n} \beta^{+}=\frac{1}{2.71(4 \pi)^{2} r_{e} m c^{2}}\left(\frac{P_{0}^{3} D_{0} \delta H^{2}\left(D_{0}\right)}{L_{T V V}^{3} E^{2}}\right)
$$

Solving this equation for $E$ and inaerting numerical values for the physical constaists, we get

$$
E=3.39 \times 10^{11}\left(\frac{P_{b}^{3} D_{0} \delta H^{2}\left(D_{0}\right)}{L_{\mathrm{J}}^{3} V^{\ell_{n} \beta^{*}}}\right)^{1 / \mathrm{A}}
$$

where $E$ is in TeV, $B$ is in megawatts, $\epsilon_{m}$ is in $\mathrm{cm}$-radians, $\beta^{*}$ is in $\mathrm{cm}$ and $L_{T, V}$ is in c-g-s units (the voual).

To get a feeling for the practical magnitude of $E$, we can use the values of emittance and beta function from the SLC.

$$
\mathrm{C}_{n} \beta^{\prime}=1.5 \times 10^{-3} \mathrm{~cm}^{2}
$$

Next we choose large values for the variables in the numerator: $P_{\mathbf{b}}=1 \mathrm{MW}$,

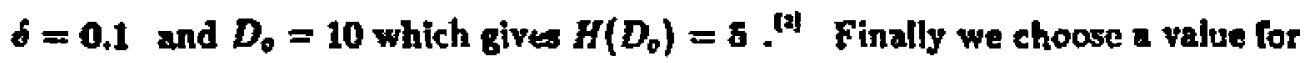
$I_{T o v}$ which would make it possible to pursue B versatile experimental program. We choose $L_{T \mathrm{r}}=10^{34} \mathrm{~cm}^{-2 \mathrm{~g}-1}$. The result is

$$
E=0.2 \mathrm{TeV} \text {. }
$$

The luminosity of this collider would be $4 \times 10^{33} \mathrm{tm}^{-3} \mathrm{~s}^{-1}$. 
If we were able to reduce the product $\left(\mathrm{f}_{*} \beta^{*}\right)$ by a divisor of one hundred, we could reach only

$$
E=0.35 \mathrm{TeV}
$$

Note that the faclors used in the numerator are all at least several times the corresponding quantities in the SLC. The bearn power is fourteen times that for which the SLC is designed for example. To seek to build a collider for a center-ofmass enerby of even $0.7 \mathrm{TeV}$ would compel us to make substantial improvements in the feasibje values of many accelerator parametera in one generation.

At the oulset we assumed that our calculations would place us in a region of variables where the ciassieal beamstrahiung formula holds. This can he verified for the exainples givill.

Finally, an addilional ingree of freedom could be introduced by consinhning non-round beams. Equztion (13) could be elaborated in terms of a "flatness parameter". Perhaps this should be done, but it does not seem likely that the upper limit on energy would be changed much.

The author thanks D. Getr, J. Patereon and M. Sande for resding and cormmenting on drafts of this note.

\section{REFERENCES}

1. J. Ree, SLAC-IUB-4073, (Sep 1986).

2. R. Hollebeek and A. Minton, Collider Note-302, SLAC Internal Memo, June 10, 1985.

\section{FIGURE CAPTION}

Fig. 1. The incoming area, $A_{0,}$ and the effective interaction area, $A$, in the cese of a pinch. 


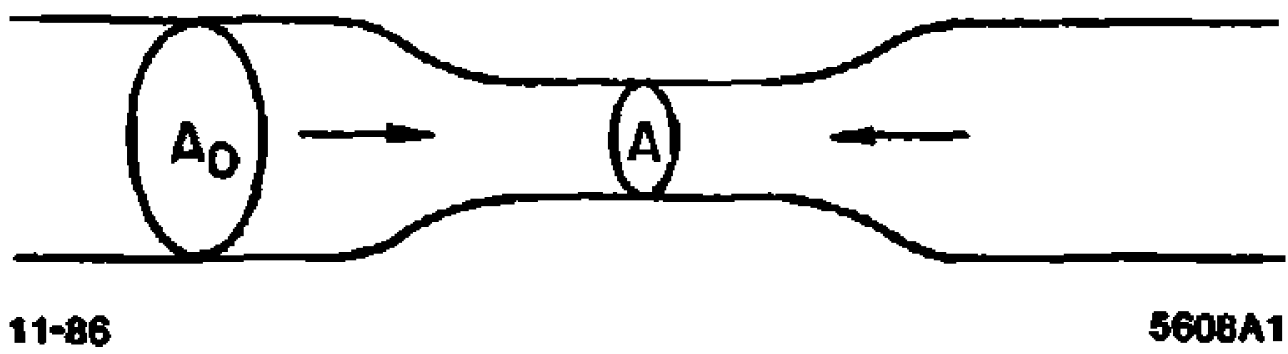

Fig. 1 